\title{
Rainfall-runoff risk characteristics of urban function zones in Beijing using the SCS-CN model
}

\author{
YAO Lei ${ }^{1}$, WEI Wei ${ }^{2}$, YU Yang ${ }^{2}$, XIAO Jun ${ }^{2},{ }^{*}$ CHEN Liding ${ }^{2}$ \\ 1. College of Geography and Environment, Shandong Normal University, Jinan 250014, China; \\ 2. State Key Laboratory of Urban and Regional Ecology, Research Center for Eco-Environmental Sciences, \\ CAS, Beijing 100085, China
}

\begin{abstract}
Urbanization significantly increases the risk of urban flooding. Therefore, quantitative study of urban rainfall-runoff processes can provide a scientific basis for urban planning and management. In this paper, the built-up region within the Fifth Ring Road of Beijing was selected as the study area. The details of land cover and urban function zones (UFZs) were identified using GIS and RS methods. On this basis, the SCS-CN model was adopted to analyze the rainfall-runoff risk characteristics of the study area. The results showed that: (1) UFZs within different levels of runoff risk varied under different rainfall conditions. The area ratio of the UFZs with high runoff risk increased from $18.90 \%$ (for rainfall return period of $1 \mathrm{a}$ ) to $54.74 \%$ (for period of $100 a$ ). Specifically, urban commercial areas tended to have the highest runoff risk, while urban greening spaces had the lowest. (2) The spatial characteristics of the runoff risks showed an obvious circular distribution. Spatial cluster areas with high runoff risk were mainly concentrated in the center of the study area, while those with low runoff risk were mainly distributed between the fourth and fifth ring roads. The results indicated that the spatial clustering characteristic of urban runoff risk and runoff heterogeneity among different UFZs should be fully considered during urban rainwater management.
\end{abstract}

Keywords: SCS-CN model; urban function zone; spatial cluster; runoff risk

\section{Introduction}

As a special ecological system, urban areas act as unified regions that integrate the residents and their surrounding environment. Urbanization alters the original environment significantly, bringing dramatic change during the transition from natural to artificial landscapes. Along with urban construction and expansion, the original land cover, such as forests and lawns, are gradually replaced by larger amounts of impervious surfaces. The land cover alterations lead to significant reduction in urban rainwater interception and infiltration capac-

\footnotetext{
Received: 2017-05-08 Accepted: 2017-06-28

Foundation: National Natural Science Foundation of China, No.41701206; The Major Program of National Natural Science Foundation of China, No.41590841

Author: Yao Lei (1989-), PhD, specialized in landscape ecology and urban hydrological process.

E-mail: alex_yaolei@126.com

"Corresponding author: Chen Liding (1965-), PhD and Professor, specialized in landscape ecology.

E-mail: liding@rcees.ac.cn
} 
ity (Shuster, 2005; Sunde et al., 2016). In addition, local climate changes deeply affect storm drainage in urban and surrounding areas, resulting in urban areas becoming vulnerable to extreme rainfall of short duration and high intensity (Milly et al., 2002; Putro et al., 2016). These factors cause increased risks from rainfall and runoff, and from storm-related flood hazards in urban regions.

As the unit by which urban functions are realized, urban function zones (UFZs) refer to the areas assigned to different types of urban (social and economic) activities. According to different urban functions, UFZs can be divided into several types (i.e., residential, commercial, educational, and industrial zones) (Tian et al., 2010). These UFZs are closely related to daily urban activities. Therefore, studying the rainfall-runoff process from the perspective of UFZs will provide a better understanding of the spatial characteristics of urban rainfall-runoff risks.

However, due to the complexity and particularity of urban planning tasks (i.e., complex urban terrain, crisscrossed underground drainage networks, and the restrictions imposed by urban management), it is hard to acquire sufficient hydrological monitoring data. This increases the difficulty of urban rainfall-runoff research (Ebrahimian et al., 2016; Zhu et al., 2016). For this reason, methods involving such as hydrological models and $3 \mathrm{~S}$ technology (GIS, RS, and GPS) are adopted for the study of urban rainfall-runoff issues (Atkinson, 2012; Gajbhiye and Mishra, 2012; Lin, 2000). All these methods help to understand, at multiple spatial scales, the mechanisms by which urbanization influences rainfall-runoff processes.

Recently, a great deal of hydrological research has been conducted in Beijing (Ouyang et al., 2012; Yao et al., 2016; Zhang et al., 2012b). However, most of these studies were focused on rainfall-runoff characteristics at the community scale, rather than urban scale. Therefore, this study aimed to explore the rainfall-runoff characteristics of the area inside Beijing's Fifth Ring Road. In this study, the Soil Conservation Service-Curve Number (SCS-CN) model and GIS/RS technology were used to extract UFZs and land-cover details, and then to analyze the rainfall-runoff among different types of UFZs, in order to identify quantitatively, the high and low risk areas of rainfall-runoff.

\section{Materials and methodology}

\subsection{Study area}

Beijing is the social, economic, and cultural center of China, and is located on the northeast edge of the North China Plain. This city has a typical continental monsoon climate, an annual average temperature of $\sim 11-12^{\circ} \mathrm{C}$, and average rainfall of $585 \mathrm{~mm}$. The rainfall is mainly concentrated in the flood season, which occurs in June-September (Yao et al., 2015).

Owing to rapid urbanization of this area, urban flooding hazards in Beijing have become more frequent. In the summer of 2012, Beijing suffered a severe flooding event that caused 78 deaths and enormous economic loss. This resulted in greater concern over urban flooding risks citywide, and a series of environmental management policies were adopted to address these issues (Pan et al., 2009). Therefore for this study, the built-up region within the Fifth Ring Road of Beijing was chosen as the study area, as shown in Figure 1.

\subsection{Data preparation}

In this study, an IKONOS image (satellite-based) was used as the spatial data source. This image 


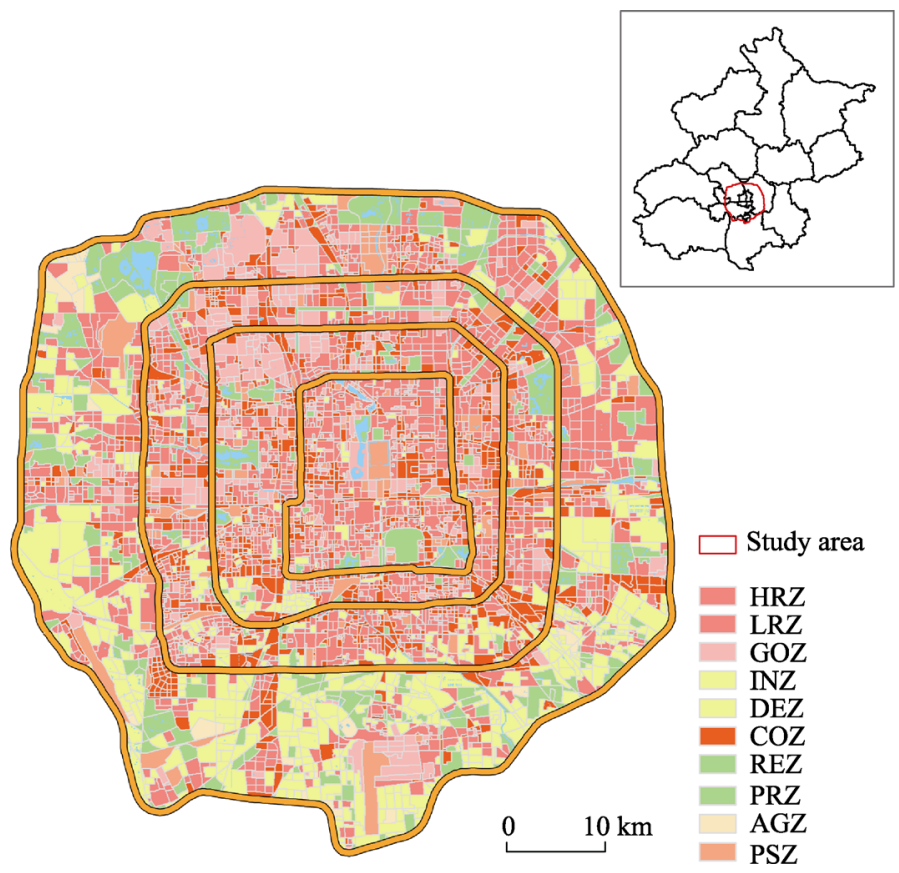

Figure 1 The study area and its urban function zones

covers the whole region within the Fifth Ring Road of Beijing. The image was acquired on July 29, 2012 (summer) to ensure its clarity and its ability to determine vegetation and other land cover information. Then, all the five image bands were subjected to band-fusion to obtain high spatial resolution $(1 \mathrm{~m} \times 1 \mathrm{~m})$.

\subsection{Methodology}

\subsubsection{Spatial identification}

Before use, the IKONOS image was first geo-rectified using ArcGIS software (version 10.1) to meet the requirements of the following land cover classification and UFZ identification.

Then, the land cover details of the study area were classified by integrating the object-oriented and decision tree classification method. The remote sensing image was partitioned into segments (objects) by grouping neighboring pixels with similar feature values. A set of characteristic parameters for each object (i.e., spatial, textural, spectral, color, and band ratio) was compiled and then transferred to multiple rule sets. The study area was finally divided into six types of land cover: impervious land, water, bare land, forest, grassland, and farmland. The overall classification precision was $85.8 \%$ and the kappa coefficient was 0.75 .

The UFZs of the study area were identified based on the IKONOS image. Referring to the UFZ identification work conducted by Sun et al. (2013), and the latest information on urban function in Beijing, this study set the standard for UFZ identification in Beijing, as shown in Table 1. This study was the first to define an urban function block (UFB) as a finer sub-area (similar to an urban block) within a UFZ. Considering that linear landscape elements in urban areas typically serve as the borders of UFZs, as well as sub-areas of urban 
Table 1 Standard of classification for urban functional zones in Beijing's five-ring areas

\begin{tabular}{|c|c|c|c|}
\hline UFZ & Abbreviation & Area (ha) & Description \\
\hline $\begin{array}{l}\text { High-density } \\
\text { residential zone }\end{array}$ & HRZ & 21187.9 & $\begin{array}{l}\text { Services for citizens; typical residential communities in } \\
\text { Beijing, including low-rise and high-rise buildings with a } \\
\text { dense population. }\end{array}$ \\
\hline $\begin{array}{l}\text { Low-density } \\
\text { residential zone }\end{array}$ & LRZ & 450.0 & $\begin{array}{l}\text { Services for citizens; lower impervious fraction; mainly } \\
\text { low-rise buildings with a sparse population. }\end{array}$ \\
\hline Government zone & $\mathrm{GOZ}$ & 6119.2 & $\begin{array}{l}\text { Services for civil servants and students; government buildings, } \\
\text { public organizations, research institutes, and campuses. }\end{array}$ \\
\hline Industry zone & INZ & 9460.1 & $\begin{array}{l}\text { Services for production workers and laborers; city infra- } \\
\text { structure and industrial factories, energy, and resources supply. }\end{array}$ \\
\hline Commercial zone & $\mathrm{COZ}$ & 10100.6 & $\begin{array}{l}\text { Services for business and commercial workers; city malls, retail } \\
\text { businesses, and public amenities such as restaurants, hotels, etc. }\end{array}$ \\
\hline Recreational zone & REZ & 9204.5 & $\begin{array}{l}\text { Services for tourists and residents; urban parks, golf courses, } \\
\text { and scenic areas with relatively high green coverage. }\end{array}$ \\
\hline Preservation zone & PRZ & 225.1 & $\begin{array}{l}\text { Services for tourists and residents; open space with natural } \\
\text { and artificial green space such as forest parks. }\end{array}$ \\
\hline Agricultural zone & AGZ & 751.9 & $\begin{array}{l}\text { Services for agricultural workers; cultivated land, green- } \\
\text { houses, and orchards. }\end{array}$ \\
\hline Public service zone & PSZ & 3704.6 & $\begin{array}{l}\text { Services for citizens, such as hospitals, libraries, museums, } \\
\text { stadiums, and city squares. }\end{array}$ \\
\hline Development zone & DEZ & 4302.1 & $\begin{array}{l}\text { Services mainly for construction workers; undeveloped open } \\
\text { space and demolition areas. }\end{array}$ \\
\hline
\end{tabular}

sewer systems, several mesh regions (i.e., UFBs) were manually delineated for the entire study area, along with urban roads and canal networks. All these UFBs were treated as independent hydrological units and geo-coded with unique urban function types according to the UFZ standard in Table 1. Finally, 10 types of UFZ were identified, including a high-density residential zone (HRZ), low-density residential zone (LRZ), government zone (GOZ), industrial zone (INZ), commercial zone (COZ), recreational zone (REZ), preservation zone (PRZ), agricultural zone (AGZ), public service zone (PSZ), and development zone (DEZ), as shown in Figure 1.

\subsubsection{Hydrological modeling}

Rainfall-runoff characteristics of UFZs were simulated using the Soil Conservation Service Curve Number (SCS-CN) model in this study. The SCS-CN model was developed by the United States Department of Agriculture (USDA), in order to study the rainfall-runoff processes in agricultural and urbanized watersheds. Many urban eschatology studies have used this model to simulate various runoff scenarios, ranging from small urban sites (e.g., highway or residential lots) to neighborhoods, to large urban watersheds (Gajbhiye and Mishra, 2012; Kadam et al., 2012; Singh et al., 2013; Zuo et al., 2016). Meanwhile, the USDA also provides a Curve Number (CN) look-up table with assignments of different types of land cover to facilitate hydrological simulation (NRCS, 1986).

Compared with natural and agricultural watersheds, urbanized areas have relatively high $\mathrm{CN}$ values due to greater impervious coverage, indicating more sensitive rainfall-runoff responses. On this basis, researchers conducted a series of studies to explore the rainfall-runoff characteristics of urbanized watersheds at multiple spatial scales (i.e., watershed (Kadam et al., 2012), community (Skotnicki and Sowiński, 2013; Yao et al., 2017; Yao et al., 2016), and plot (Singh et al., 2013)). In addition, many distributed hydrological models (i.e., SWAT, 
SWMM, and HEC-HMS) are based on the theory of the SCS-CN model for estimating runoff (Baker and Miller, 2013; Zhou et al., 2013). These factors demonstrate that the SCS-CN model can well estimate the rainfall-runoff risk in highly urbanized areas.

Minimal input data are needed for this model to simulate surface runoff. Specifically, the calculations require only rainfall abstraction, without considering other complex factors (e.g., groundwater recharge and base flow). Three parameters are used to calculate surface runoff: rainfall depth, initial abstraction of the rainfall, and the potential maximum storage of the soil (NRCS, 1986). The model formula is as follows:

$$
\begin{gathered}
Q=\frac{\left(P-I_{a}\right)^{2}}{P-I_{a}+S} \\
S=\frac{25400}{C N}-254
\end{gathered}
$$

where $Q$ is the runoff depth $(\mathrm{mm}), P$ is the rainfall depth $(\mathrm{mm}), I_{a}$ is the initial abstraction of the rainfall $(\mathrm{mm})$, and $S$ represents potential maximum soil-water capacity. A quantitative relationship exists between $I_{a}$ and $S\left(I_{a}=0.2 S\right)$ (NRCS, 1986). $C N$ is a dimensionless parameter (ranging from 0 to 100), representing the hydrological performance of various land cover categories. Higher $C N$ indicates greater potential for surface runoff and less surface storage.

According to the user manual for the SCS-CN model, reliable hydrological modeling depends on determination of the CN value for each type of land cover (NRCS, 1986). This task needs to make explicit the hydrology soil groups (HSG), land cover details, and antecedent soil moisture condition (AMC) (Fan et al., 2013). USDA has created several different hydrologic soil groups (A, B, C, and D groups: HSGs), to represent different infiltration capacities of soils. To determine the HSGs for the city of Beijing, Fu et al. (2013) found that the soils of Beijing can be classified as B-group after testing the saturated hydraulic conductivity of these soils using the constant head method. Land cover details of the study area were determined from the IKONOS image. Then, referring to the CN look-up table (NRCS, 1986), CN values were assigned to the various land-cover types and AMCs of the study area, as shown in Table 2.

For design of urban drainage systems, rainfall intensity can be determined according to a rainfall formula, and the rainfall duration can refer to the average runoff concentration time of the drainage area. In Beijing, runoff concentration time was usually less than $120 \mathrm{~min}$, representing a relatively quick flow time. Therefore, in this study, different rainfall conditions were selected with various return periods according to the rainfall formula appropriate in Beijing (Wang et al., 2011). These rainfall return periods were labeled 1a, 3a, 5a, 10a, 25a, $50 \mathrm{a}$, and $100 \mathrm{a}$; and the rainfall duration was set as $120 \mathrm{~min}$. The de-

Table 2 Curve numbers assigned with various land cover types and antecedent moisture conditions (AMC)

\begin{tabular}{lccc}
\hline \multicolumn{1}{c}{ Land use } & AMC I & AMC II $^{\text {b }}$ & AMC III \\
\hline Impervious land & 98 & 98 & 98 \\
Farmland & 60 & 78 & 90 \\
Forest & 37 & 58 & 78 \\
Grassland & 40 & 61 & 80 \\
Bare land & 81 & 91 & 97 \\
Water $^{\text {a }}$ & 0 & 0 & 0 \\
\hline
\end{tabular}

${ }^{a}$ Runoff generated from water do not exert extra influence on surrounding landscapes, thus its $\mathrm{CN}$ value can be treated as 0 ;

${ }^{\mathrm{b}}$ Moderate antecedent moisture condition is selected to represent the average rainfall-runoff conditions of Beijing (NRCS, 1986). 
signed rainfall amounts $(\mathrm{P})$ were $(39.7,55.2,62.4,72.1,84.9,94.7$, and 104.4) $\mathrm{mm}$, respectively.

Finally, the SCS-CN model was built using the modeling tools in ArcGIS. The runoff characteristics under different rainfall conditions were simulated after inputting the CN values and rainfall data. The rainfall-runoff data for different types of UFZ were analyzed using spatial analysis and analysis of variance (ANOVA in SPSS), to investigate the runoff differences between the different UFZs.

\subsubsection{Runoff risk identification}

Spatial autocorrelation analysis can identify the potential aggregation characteristics of geographical phenomena. This method can use indicators including the global autocorrelation coefficient (Moran's I) and partial autocorrelation coefficient (Local Moran's I) to describe the spatial characteristics.

Moran's $I$ can be calculated by the following formula:

$$
I=\frac{n * \sum_{i}^{n} \sum_{j}^{n} w_{i j} *\left(x_{i}-\bar{x}\right)\left(x_{j}-\bar{x}\right)}{\sum_{i}^{n} \sum_{j}^{n} w_{i j} * \sum_{i}^{n}\left(x_{i}-\bar{x}\right)^{2}}
$$

where, $n$ is the number of geographical phenomena for analysis, $x_{i}$ and $x_{j}$ are the values of geographical phenomena of $i$ and $j, x$ is the average value of all the geographical phenomena, $w_{i j}$ is the weighting matrix between geographical phenomena of $i$ and $j$. The $I$ value ranges from -1 to $1: I>0$ indicates positive spatial autocorrelation (aggregate spatial distribution condition); $I<0$ indicates negative spatial autocorrelation (discrete spatial distribution condition); and $I=0$ indicates no spatial autocorrelation (random spatial distribution condition).

The partial autocorrelation coefficient is visible on the LISA map, representing the specific spatial distribution conditions for the local area. From the LISA map, the study area was divided into four types of region with different correlation significance, showing higher autocorrelation (HH), lower autocorrelation (LL), high-low negative correlation (HL), and low-high negative correlation (LH). For this purpose, the $\mathrm{HH}$ regions can be identified as "hot spot areas", the LL regions, by contrast, are "cold spot areas"; and the HL and LH regions indicate "isolated areas" with significant contrast.

This study conducted a spatial autocorrelation analysis to explore the spatial characteristics of the rainfall-runoff risks of different types of UFZs using Geoda software. This was done to make explicit the regularity of the spatial distribution of the "hot spots" and "cold spots" in the study area.

\section{Results and discussions}

\subsection{Details of urban function zones}

Eventually, a total of 5116 UFBs were delineated within the study area, as shown in Table 1. The largest were the residential (including HRZ and LRZ: $217.17 \mathrm{~km}^{2}$ ) and industrial (including INZ and DEZ: $138.75 \mathrm{~km}^{2}$ ) zones. These were followed by the commercial zone (COZ: $101.89 \mathrm{~km}^{2}$ ), greening zone (REZ, PRZ, and AGZ: $102.27 \mathrm{~km}^{2}$ ), educational and 
governmental zone (GOZ: $62.00 \mathrm{~km}^{2}$ ), and the public zone (PSZ: $37.67 \mathrm{~km}^{2}$ ).

Gradational distribution characteristics of the UFZs were found along the ring roads of the study area, as shown in Figure 1. Within the Third Ring Road, the composition of UFZs showed slight differences between the ring roads. Outside the Third Ring Road, the proportion of commercial land gradually declined, while that of industrial land (INZ and DEZ) increased. Between the fourth and fifth ring roads, the proportions of green land (REZ, PRZ, and AGZ) and industrial land both increased significantly. This reflected the concentric mode of development in Beijing.

In addition, as shown in Figure 2, the land cover composition of these UFZs showed obvious differences. Among them, HRZ, INZ, COZ, GOZ, and PSZ had similar land cover composition, with relatively high impervious coverage ( $>70 \%)$. Compared to HRZ, LRZ exhibited a lower impervious ratio and greater vegetation coverage. The urban development region, DEZ, had the greatest coverage of bare land; while REZ and PRZ had greater forest coverage, indicating their recreational and ecological conservation functions. AGZ had the most farmland and a small amount of impervious surfaces (mainly these were farming sheds and greenhouses).

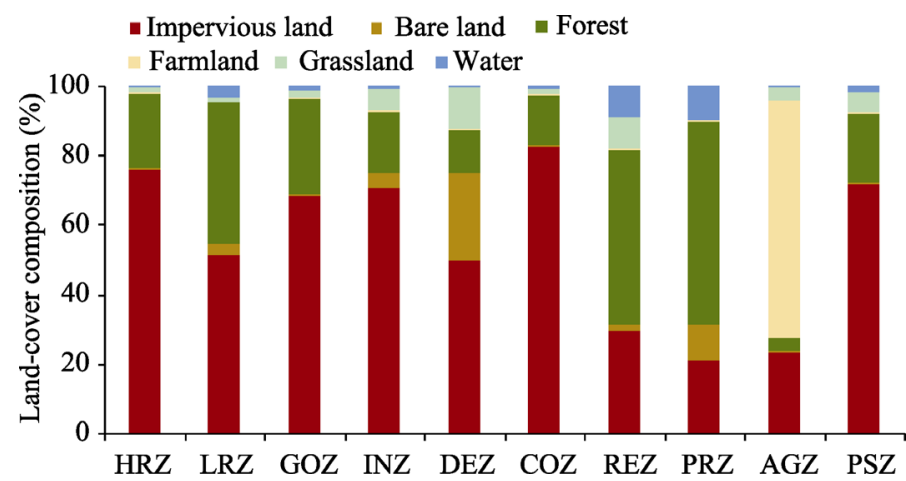

Figure 2 Land-cover composition of each type of urban functional zone

\subsection{Runoff analyses}

\subsubsection{Runoff characteristics of the study area}

The average runoff as well as the runoff ratio ( $\alpha=$ runoff depth/rainfall depth) for the whole study area increased with increase in the rainfall return period, as shown in Figure 3. Specifically, the average runoff increased from $24.35 \mathrm{~mm}$ (under the rainfall return period of 1a) to $76.01 \mathrm{~mm}$ (under the rainfall return period of 100a). The corresponding $\alpha$ rose from 0.51 (1a) to $0.64(100 \mathrm{a})$, showing a logarithmic trend $\left(y=0.0705 \ln (x)+0.4983, R^{2}=0.97\right)$. However, the increasing trend slowed as the rainfall amount increased (Figure 3). This is mainly because $29 \%$ of the land surfaces in the study area were pervious. According to the hydrology budget principle, the rainfall falling on soil should first meet the budget for the depression storage of the adherent land surface, then generates runoff (Armson et al., 2013). Later, $\alpha$ increased from ' 0 ' and tended to be stable (the maximum

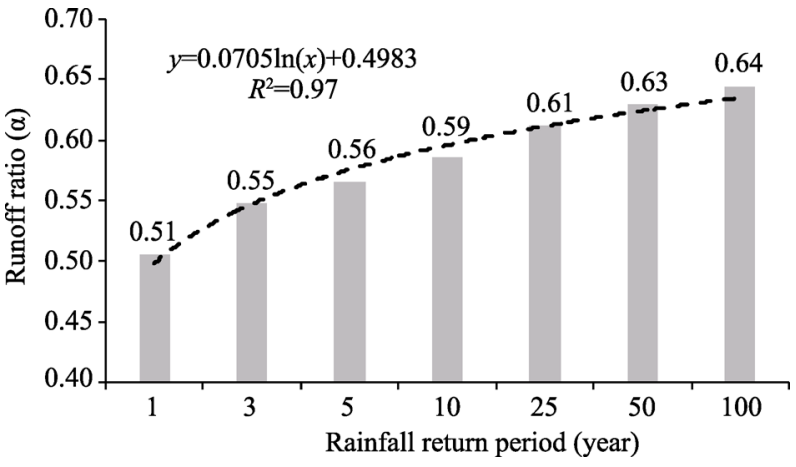

Figure 3 Average runoff ratios of the study area under different rainfall return periods 
value) after the land surface reached condition of steady infiltration.

\subsubsection{Runoff characteristics of urban function zones}

The ANOVA analysis showed significant differences in the runoff among the UFZs under different rainfall conditions, and detailed runoff information for all these UFZs is shown in Table 5. Due to the highest greening (forest, grassland, and farmland, as shown in Figure 2) and water coverage, and the lowest imperviousness (leading to higher capacity of intercept and infiltration for rainwater), the runoff amounts generated from REZ, PRZ, and AGZ were the lowest $(<15 \mathrm{~mm}$ under the rainfall return period of 1a). However, Table 2 shows that $\mathrm{CN}_{\text {farmland }}>\mathrm{CN}_{\text {grassland }}>\mathrm{CN}_{\text {forest }}$; thus, more runoff was generated from AGZ (included the most farmland) than from REZ and PRZ. By contrast, with relatively high imperviousness, COZ and INZ generated similarly large amounts of runoff under all rainfall conditions. Runoff generated from GOZ, PSZ, and HRZ reached greater amounts $(>24 \mathrm{~mm}$ under the rainfall return period of 1a), while LRZ and DEZ (with higher greening, bare land, and coverage) generated smaller amounts of runoff than did GOZ, PSZ, and HRZ.

Table 5 Comparison of the average runoff volume in each urban functional zone (UFZ) in different return periods of rainfall $(\mathrm{mm})$

\begin{tabular}{cccccccc}
\hline UFZ & $1 \mathrm{a}$ & $3 \mathrm{a}$ & $5 \mathrm{a}$ & $10 \mathrm{a}$ & $25 \mathrm{a}$ & $50 \mathrm{a}$ & $100 \mathrm{a}$ \\
\hline GOZ & $24.76 \pm 4.14 \mathrm{e}$ & $36.40 \pm 5.78 \mathrm{de}$ & $42.02 \pm 6.46 \mathrm{de}$ & $49.77 \pm 7.31 \mathrm{~d}$ & $60.25 \pm 8.32 \mathrm{~d}$ & $68.45 \pm 9.02 \mathrm{~d}$ & $76.70 \pm 9.66 \mathrm{~d}$ \\
$\mathrm{COZ}$ & $27.74 \pm 3.71 \mathrm{f}$ & $40.58 \pm 5.17 \mathrm{f}$ & $46.70 \pm 5.77 \mathrm{f}$ & $55.06 \pm 6.52 \mathrm{e}$ & $66.28 \pm 7.42 \mathrm{e}$ & $74.99 \pm 8.04 \mathrm{e}$ & $83.69 \pm 8.60 \mathrm{e}$ \\
AGZ & $12.00 \pm 4.83 \mathrm{~b}$ & $21.12 \pm 6.22 \mathrm{~b}$ & $25.87 \pm 6.80 \mathrm{~b}$ & $32.66 \pm 7.52 \mathrm{~b}$ & $42.17 \pm 8.40 \mathrm{bc}$ & $49.79 \pm 9.02 \mathrm{c}$ & $57.57 \pm 9.59 \mathrm{c}$ \\
PSZ & $25.06 \pm 5.10 \mathrm{e}$ & $36.84 \pm 7.11 \mathrm{de}$ & $42.51 \pm 7.94 \mathrm{de}$ & $50.33 \pm 8.96 \mathrm{~d}$ & $60.90 \pm 10.19 \mathrm{~d}$ & $69.16 \pm 11.04 \mathrm{~d}$ & $77.45 \pm 11.81 \mathrm{~d}$ \\
HRZ & $24.90 \pm 3.55 \mathrm{e}$ & $36.60 \pm 4.96 \mathrm{de}$ & $42.24 \pm 5.54 \mathrm{de}$ & $50.02 \pm 6.26 \mathrm{~d}$ & $60.54 \pm 7.12 \mathrm{~d}$ & $68.77 \pm 7.72 \mathrm{~d}$ & $77.03 \pm 8.27 \mathrm{~d}$ \\
LRZ & $17.56 \pm 5.55 \mathrm{c}$ & $26.45 \pm 7.78 \mathrm{c}$ & $30.93 \pm 8.70 \mathrm{c}$ & $37.27 \pm 9.85 \mathrm{c}$ & $46.08 \pm 11.22 \mathrm{c}$ & $53.12 \pm 12.18 \mathrm{c}$ & $60.31 \pm 13.05 \mathrm{c}$ \\
INZ & $25.42 \pm 5.78 \mathrm{ef}$ & $37.43 \pm 7.98 \mathrm{ef}$ & $43.21 \pm 8.88 \mathrm{ef}$ & $51.16 \pm 10 \mathrm{de}$ & $61.88 \pm 11.34 \mathrm{de}$ & $70.26 \pm 12.26 \mathrm{de}$ & $78.66 \pm 13.09 \mathrm{de}$ \\
DEZ & $22.27 \pm 7.03 \mathrm{~d}$ & $33.59 \pm 9.61 \mathrm{~d}$ & $39.10 \pm 10.68 \mathrm{~d}$ & $46.74 \pm 12 \mathrm{~d}$ & $57.12 \pm 13.57 \mathrm{~d}$ & $65.26 \pm 14.66 \mathrm{~d}$ & $73.46 \pm 15.65 \mathrm{~d}$ \\
REZ & $13.55 \pm 6.40 \mathrm{~b}$ & $20.83 \pm 8.94 \mathrm{~b}$ & $24.64 \pm 9.99 \mathrm{~b}$ & $30.15 \pm 11.3 \mathrm{~b}$ & $37.97 \pm 12.86 \mathrm{~b}$ & $44.33 \pm 13.94 \mathrm{~b}$ & $50.90 \pm 14.93 \mathrm{~b}$ \\
PRZ & $7.36 \pm 3.10 \mathrm{a}$ & $12.39 \pm 4.48 \mathrm{a}$ & $15.28 \pm 5.06 \mathrm{a}$ & $19.64 \pm 5.8 \mathrm{a}$ & $26.12 \pm 6.69 \mathrm{a}$ & $31.54 \pm 7.31 \mathrm{a}$ & $37.26 \pm 7.88 \mathrm{a}$ \\
\hline
\end{tabular}

Note: The runoff values with different letters in the same column show significant difference (data represented as "means \pm standard deviation", $p<0.05)$; the abbreviations of these urban function zones were: high-density residential zone (HRZ), low-density residential zone (LRZ), government zone (GOZ), industrial zone (INZ), commercial zone (COZ), recreational zone (REZ), preservation zone (PRZ), agricultural zone (AGZ), public service zone (PSZ), and development zone (DEZ)

As the rainfall return period increased, the runoff of all the UFZs rose and the runoff gaps among them narrowed gradually (Table 5). In the cases under lighter rainfall conditions, more runoff was mainly generated from the UFZs with higher impervious coverage (e.g., COZ, HRZ); while runoff generated from some types of UFZs (e.g., DEZ) became similarly high under heavier rainfall conditions.

\subsection{Runoff risk analyses}

\subsubsection{Runoff risk categorization}

The Code for Design of Outdoor Wastewater Engineering (Ministry of Construction of China) requires that necessary rainwater penetration and regulation countermeasures should be carried out for an urban built-up region if its runoff ratio $(\alpha)$ exceeds 0.7 (GB50014-2006, 
2013). Referring to this rule, in this study, the whole study area was divided into five types of runoff risk area according to the runoff ratio $(\alpha)$ of each UFZ. The classification standard is shown in Table 3.

As shown in Figure 4, the proportions of the UFZs with the highest runoff risk increased significantly with increase in the rainfall return period. For the rainfall return period of $1 \mathrm{a}$, the
Table 3 Class assignments of the runoff risk areas

\begin{tabular}{ll}
\hline Rainfall-runoff risk level & Runoff ratio $(\alpha)$ \\
\hline Lowest risk & $\alpha<0.35$ \\
Lower risk & $0.35 \leqslant \alpha<0.5$ \\
Moderate risk & $0.5 \leqslant \alpha<0.6$ \\
Higher risk & $0.6 \leqslant \alpha<0.7$ \\
Highest risk & $0.7 \leqslant \alpha$ \\
\hline
\end{tabular}
total area of the UFZs with the highest runoff risk accounted for $18.90 \%$ of the study area; while for the rainfall return period of $10 \mathrm{a}$, this proportion increased to $38.62 \%$. It continually increased to more than $50 \%$ when the rainfall condition had the return period of $100 \mathrm{a}$.

(a)

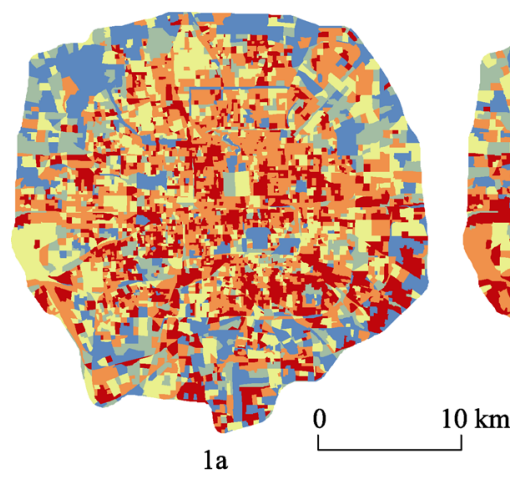

(b)

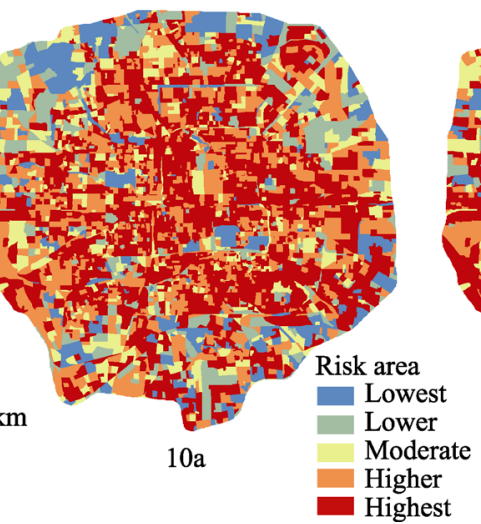

(c)

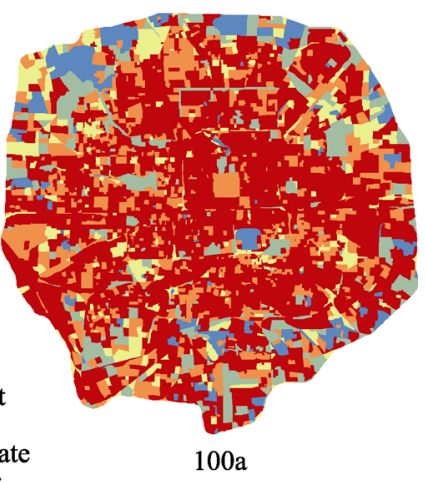

Figure 4 Spatial distribution chart of runoff risk area under 3 types of rainfall conditions (1a, 10a, 100a)

In addition, proportions of UFZs within each runoff risk area showed obvious differences. Taking the rainfall condition for the return period of 10a as example (Figure 4 and Table 4), the urban greening UFZs (PRZ and REZ) occupied $86.07 \%$ of the area with the lowest runoff risk, which were mainly distributed outside the Fourth Ring Road, as well as in a few scattered urban parks in the central urban area. The rest of these greening UFZs belonged

Table 4 Proportions of urban functional zones within each level runoff risk area (under the rainfall return period of $10 \mathrm{a})$

\begin{tabular}{cccccc}
\hline \multirow{2}{*}{$\begin{array}{c}\text { Urban function } \\
\text { zone }\end{array}$} & \multicolumn{5}{c}{ Area ratio for each level runoff risk (\%) } \\
\cline { 2 - 6 } & Highest risk & Higher risk & Moderate risk & Lower risk & Lowest risk \\
\hline HRZ & 37.41 & 46.26 & 32.98 & 8.21 & 0.52 \\
LRZ & 0.04 & 0.50 & 0.29 & 4.16 & 0.40 \\
GOZ & 6.98 & 11.77 & 18.25 & 8.69 & 2.00 \\
INZ & 15.18 & 16.65 & 17.00 & 12.22 & 4.72 \\
DEZ & 5.17 & 7.27 & 10.68 & 7.30 & 3.74 \\
COZ & 29.88 & 8.87 & 6.83 & 3.97 & 0.68 \\
REZ & 0.27 & 1.30 & 8.38 & 36.58 & 84.17 \\
PRZ & - & - & - & 1.39 & 1.90 \\
AGZ & - & 0.35 & 1.45 & 6.67 & 10.81 \\
PSZ & 5.07 & 7.03 & 4.14 & 0.83 \\
\hline
\end{tabular}


mainly to the runoff areas with lower and moderate risk. On the contrary, most of the UFZs with the highest runoff risk were distributed within the Fourth Ring Road, mainly HRZ (37.41\%), INZ (15.18\%), and COZ (29.88\%). However, the proportions of GOZ and DEZ in the area of the highest runoff risk were relatively low, at $6.98 \%$ and $5.17 \%$, respectively.

\subsubsection{Spatial cluster analysis for runoff risk}

The results of global autocorrelation analysis showed that the value of Moran's $I$ coefficient was $0.139(p<0.001)$, indicating that the spatial distribution of the runoff risk areas in the study area presented significant aggregation characteristics.

The local autocorrelation analysis result is shown in Figure 5. HH areas (marked in red) illustrated the spatial cluster of UFZs with high runoff risk, and were mainly distributed in the urban core area (average runoff ratio of 0.82). These areas were mainly HRZ (nearly $41 \%$ ) and $\mathrm{COZ}$ (nearly $36 \%$ ), ac-

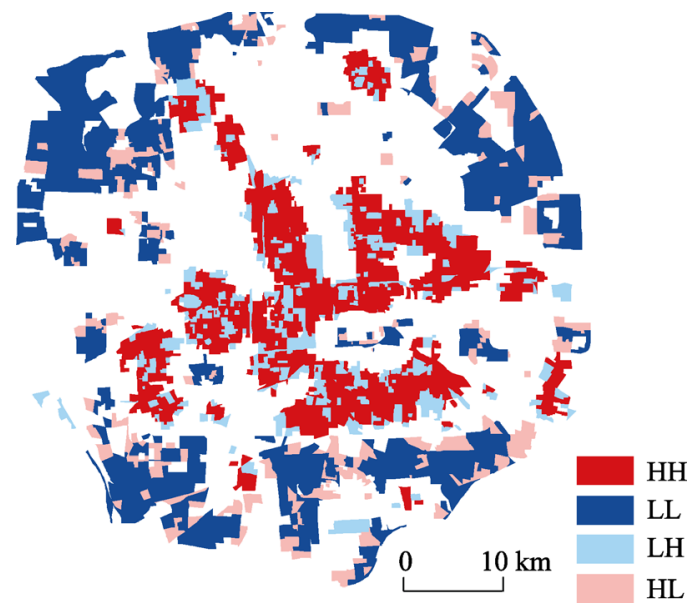

Figure 5 LISA map for runoff risk analysis counting for nearly $80 \%$ of the impervious surfaces.

LL areas (marked in blue) showed the spatial cluster of UFZs with low runoff risk, which were mainly distributed between the fourth and fifth ring roads. The UFZ composition of this area was mainly greening UFZs (nearly $32 \%$, such as large urban parks and natural greenbelts) as well as some scattered LRZ (nearly 22\%). The impervious coverage of these areas was lower than the average level $(65 \%)$ of the whole study area, and their average runoff ratio reached 0.56 (far lower than that of the $\mathrm{HH}$ areas).

\subsection{Implications}

As shown in Figure 5, the $\mathrm{HH}$ areas are mainly located in the core built-up region of Beijing, with a mostly flat landscape (Yao et al., 2015). Here, the municipal drainage system is the main provision for discharge of rainwater. Also, this area is away from the waterways (that might accept water from urban drainage) of the urban watershed. These factors mean that the surface runoff cannot be discharged quickly enough; thus increasing the drainage burden of these areas. These areas constitute the cluster of UFZs with high runoff risks, which typically deliver excess rainfall to the surrounding areas. When confronted with heavy rainfall, these areas are susceptible to urban flooding due to supersaturation of the drainage system. Even worse, the $\mathrm{HH}$ areas are mainly urban commercial and residential areas, where higher social and economic loss due to urban flooding is more likely than in other urban areas. Therefore, these $\mathrm{HH}$ areas should be paid more attention during future municipal drainage planning, to strengthen their drainage systems.

This study also demonstrated that the cluster areas with low runoff risk (LL areas) were mainly urban green spaces that have been shown to improve canopy interception, evaporation, and land surface infiltration to mitigate excessive rainfall and runoff efficiently (Dunnett et al., 2008; Gill et al., 2007; Jarden et al., 2015). Zhang et al. (2012a) and Yao et al. (2015) explored the potential reduction in urban runoff by green spaces in Beijing, and 
estimated the amount to be $2494 \mathrm{~m}^{3} \cdot$ ha (in 2009) and $4258 \mathrm{~m}^{3} \cdot$ ha (in 2012). This indicates that the urban green spaces can thus not only provide huge ecological benefits, but can also greatly alleviate the pressure on urban drainage. Therefore, rational urban green space planning and construction are needed while strengthening the construction of drainage facilities in the urban areas with high runoff risk.

During the planning of urban flood control, the differences in runoff risks among the UFZs should be fully recognized. These differences are mainly caused by the heterogeneities in landscape patterns and configurations of these UFZs (Su et al., 2017). Thus, based on different conditions of rainfall or flood return periods, how to arrange the urban and UFZ landscape in ways more scientific and reasonable, becomes the key solution for future urban rainwater management. Meanwhile, different drainage schemes are needed to accommodate the drainage needs of different UFZs with various runoff risks.

In addition, the "advantages" of the urban area itself should be put to full use to alleviate the drainage pressure from UFZs with high runoff risks. Based on the "source-sink" landscape theory (Jiang et al., 2013), the HH areas (Figure 5) could be treated as the "source" areas for urban runoff, with the LH areas (the light blue area in Figure 5, indicating the transitional regions between the UFZs with high and low runoff risks) as the "sink" areas. By building landscape corridors (i.e., diversion canals, drainage pipelines) for runoff drainage between the $\mathrm{HH}$ and $\mathrm{LH}$ areas, redundant rainwater from $\mathrm{HH}$ areas can be conveyed to $\mathrm{LH}$ areas timely. This task could not only alleviate the flooding risk of UFZs with high runoff risks efficiently, but also reduce the construction cost for building drainage systems and improve the urban water conservation function.

\section{Conclusions}

Urbanization will be an inevitable trend in China for a long time. Thus, relieving the urban flood hazard caused by urbanization should be treated as a long-term goal for urban planning and management. In this study, quantitative research was conducted on the rainfall-runoff characteristics within the built-up region of Beijing, which may provide scientific implications for science-based urban planning and management. The conclusions from the study results can be as follows.

(1) The average runoff ratio of the whole study area increases with increase of the rainfall return period. However, spatial differences in the runoff of different UFZs were found: the low runoff risk areas were mainly distributed outside the Fourth Ring Road; the areas with higher runoff risks were mainly distributed within the Fourth Ring Road (mainly commercial and residential areas).

(2) The runoff characteristics varied significantly among different UFZs. The main reason was the degree of impervious coverage within the different UFZs.

(3) A significantly positive spatial autocorrelation of runoff risk was found in the study area, and showed a spatial pattern with a cluster region of higher runoff risks within the urban center, and a circular distribution pattern of lower runoff risks around the Fifth Ring Road. In particular, the runoff ratio of the high runoff risk areas (HH: composed of commercial and residential areas) was higher than that of the whole study area. The low runoff risk areas (LL) were mainly composed of urban greening spaces.

(4) The emphasis in urban planning should be put on UFZs with greater runoff area (the 
$\mathrm{HH}$ zones), in order to alleviate risks from urban runoff. Meanwhile, the heterogeneity of the landscape pattern should be fully considered to tap potential ecological advantages and thereby reduce the pressure on the urban drainage system.

\section{References}

Armson D, Stringer P, Ennos A R, 2013. The effect of street trees and amenity grass on urban surface water runoff in Manchester, UK. Urban Forestry \& Urban Greening, 12(3): 282-286.

Atkinson S, 2012. A storm water runoff investigation using GIS and remote sensing [D]. Unviersity of North Texas.

Baker T J, Miller S N, 2013. Using the Soil and Water Assessment Tool (SWAT) to assess land use impact on water resources in an East African watershed. Journal of Hydrology, 486(8): 100-111.

Dunnett N, Nagase A, Booth R et al., 2008. Influence of vegetation composition on runoff in two simulated green roof experiments. Urban Ecosystems, 11(4): 385-398.

Ebrahimian A, Gulliver J S, Wilson B N, 2016. Effective impervious area for runoff in urban watersheds. Hydrological Processes, 30(20): 3717-3729.

Fan F L, Deng Y B, Hu X F et al., 2013. Estimating composite curve number using an Improved SCS-CN Method with Remotely Sensed Variables in Guangzhou, China. Remote Sensing, 5(3): 1425-1438.

Fu S H, Wang H Y, Wang X L et al., 2013. The runoff curve number of SCS-CN method in Beijing. Geographical Research, 32(5): 797-807. (in Chinese)

Gajbhiye S, Mishra S, 2012. Application of NRSC-SCS curve number model in runoff estimation using RS \& GIS, International Conference on Advances in Engineering, Science and Management, IEEE, 346-352.

GB50014, 2013. Code for Design of Outdoor Wastewater Engineering. (in Chinese)

Gill S, Handley J, Ennos A et al., 2007. Adapting cities for climate change: The role of the green infrastructure. Built Environment, 33(1): 115-133.

Jarden K M, Jefferson A J, Grieser J M, 2015. Assessing the effects of catchment-scale urban green infrastructure retrofits on hydrograph characteristics. Hydrological Processes, 291(1): 6-14.

Jiang M, Chen H, Chen Q, 2013. A method to analyze "source-sink" structure of non-point source pollution based on remote sensing technology. Environmental Pollution, 182: 135-140.

Kadam A K, Kale S S, Pande N N et al., 2012. Identifying potential rainwater harvesting sites of a semi-arid, basaltic region of Western India, using SCS-CN method. Water Resources Management, 26(9): 2537-2554.

Lin F T, 2000. GIS-based information flow in a land-use zoning review process. Landscape and Urban Planning, 52(1): 21-32.

Milly P, Wetherald R, Dunne K et al., 2002. Increasing risk of great floods in a changing climate. Nature, 415 : 514-517.

NRCS, 1986. Urban hydrology for small watersheds. Technical Release, 55: 2-6.

Ouyang W, Guo B, Hao F et al., 2012. Modeling urban storm rainfall runoff from diverse underlying surfaces and application for control design in Beijing. Journal of Environmental Management, 113(1): 467-473.

Pan A, Zhang S, Meng Q et al., 2009. Initial concept of stormwater and flood management in Beijing city. China Water \& Wastewater, 25(22): 9-12. (in Chinese)

Putro B, Kjeldsen T R, Hutchins M G et al., 2016. An empirical investigation of climate and land-use effects on water quantity and quality in two urbanising catchments in the southern United Kingdom. Science of The Total Environment, 548/549: 164-172.

Shuster W D, Bonta J, Thurston H et al., 2005. Impacts of impervious surface on watershed hydrology: A review. Urban Water Journal, 2(4): 263-275.

Singh P K, Yaduvanshi B K, Patel S et al., 2013. SCS-CN based quantification of potential of rooftop catchments and computation of ASRC for rainwater harvesting. Water Resources Management, 27(7): 2001-2012.

Skotnicki M, Sowiński M, 2013. The influence of depression storage on runoff from impervious surface of urban 
catchment. Urban Water Journal, 12(3): 207-218.

Su M, Zheng Y, Hao Y et al., 2017. The influence of landscape pattern on the risk of urban water-logging and flood disaster. Ecological Indicators, doi:10.1016/j.ecolind.2017.03.008

Sun R, Lü Y, Chen L et al., 2013. Assessing the stability of annual temperatures for different urban functional zones. Building and Environment, 65(7): 90-98.

Sunde M, He H S, Hubbart J A et al., 2016. Forecasting streamflow response to increased imperviousness in an urbanizing Midwestern watershed using a coupled modeling approach. Applied Geography, 72: 14-25.

Tian G J, Wu J G, Yang Z F, 2010. Spatial pattern of urban functions in the Beijing metropolitan region. Habitat International, 34(2): 249-255.

Wang Q, Zhang X, Wei M et al., 2011. Research summary of planning and design standards for storm water system in Beijing city. Water \& Wastewater Engineering, 37(10): 34-39.

Yao L, Chen L, Wei W, 2017. Exploring the linkage between urban flood risk and spatial patterns in small urbanized catchments of Beijing, China. International Journal of Environmental Research and Public Health, 14(3): 239.

Yao L, Chen L, Wei W et al., 2015. Potential reduction in urban runoff by green spaces in Beijing: A scenario analysis. Urban Forestry \& Urban Greening, 14(2): 300-308.

Yao L, Wei W, Chen L, 2016. How does imperviousness impact the urban rainfall-runoff process under various storm cases? Ecological Indicators, 60: 893-905.

Zhang B, Xie G, Zhang C et al., 2012a. The economic benefits of rainwater-runoff reduction by urban green spaces: A case study in Beijing, China. Journal of Environmental Management, 100(10): 65-71.

Zhang X, Zhang X, Hu S et al., 2012b. Runoff and sediment modeling in a peri-urban artificial landscape: Case study of Olympic Forest Park in Beijing. Journal of Hydrology, 485: 126-138.

Zhou F, Xu Y, Chen Y et al., 2013. Hydrological response to urbanization at different spatio-temporal scales simulated by coupling of CLUE-S and the SWAT model in the Yangtze River Delta region. Journal of Hydrology, 485: 113-125.

Zhu Z, Chen Z, Chen X et al., 2016. Approach for evaluating inundation risks in urban drainage systems. Science of The Total Environment, 553: 1-12.

Zuo D, Xu Z, Yao W et al., 2016. Assessing the effects of changes in land use and climate on runoff and sediment yields from a watershed in the Loess Plateau of China. Science of The Total Environment, 544: 238-250. 